\title{
Analysis of energy generation by air-water heat pumps for individual building heating systems
}

\author{
Sergey Kuzmin* \\ Federal State Budget Higher Education Institution, Angara State Technical University, 665835 \\ Angarsk, Russia
}

\begin{abstract}
The work provides a method of determining the number of energy components of the heating system of residential individual buildings with air-to-water heat pumps in the conditions of changing potential of heatcontaining environment for different climatic areas. On the basis of the analytical and empirical dependencies obtained, reflecting the connection between the energy indicators of the heating-heat pump system, the heating system and heat pumps were analyzed during the heating period. Graphic dependences on energy consumption and thermal energy production on climatic characteristics - temperature and duration of its standing for the characteristic points of the country's climatic zones - "moderate-cold," "moderate" and "warm with mild winter" are given. Conclusions have been drawn about the possibility and prospects of using heat pumps as heat generators in heating systems.
\end{abstract}

\section{Introduction}

Obtaining thermal energy from renewable sources is an attractive idea in itself, but the effectiveness of this process depends on the potential of the original - heat-containing environment and the features of the thermodynamic cycle of devices (heat generators). In addition, when choosing a thermal energy source, it is necessary to take into account the features of the heat-consuming system and, accordingly, to represent its ability to meet the needs of the system during the entire period of operation.

Individual heating systems are generally focused on their own thermal energy generator, based on the conversion of primary energy (gas, electricity, solid fuel, renewable energy). The required capacity of heat generators is relatively small $(10-40) \mathrm{KW}$, which presents a variety of options for selecting equipment from traditional water boilers to devices using renewable energy of the atmosphere, natural water sources, soil with relatively low temperature potential [1-5]. The thermal energy contained in these environments is extracted by heat pumps with increased temperature capacity sufficient for use in the building's heatconsuming systems.

The heating system's heat consumption regime during the operating period is not constant and depends on the nature of the change in the temperature of the outdoor air. And the lower the temperature of the environment, the greater the need of the system for thermal energy. And if in traditional heat sources this problem is solved by changing the consumption of

\footnotetext{
*Corresponding author: sergey.kuzmin@mail.ru
} 
primary energy, then in alternative sources this possibility is absent. Therefore, it is important to present the real characteristics of heat generators used in heating systems, in order to objectively assess their capabilities and select the calculation parameters.

\section{Study methodology}

This paper provides the results of the assessment of thermal energy generation by air-water heat pumps during the heating period in the conditions of the changing potential of the heatcontaining environment - outdoor air.

The technique is based on the use of analytical dependencies and empirical characteristics of equipment and models of statistical parameters of the outdoor environment.

\section{Study results}

A feature of the design of the heating system of an individual residential building with its own energy source is the ability to assign calculated conditions when determining the power of the source. Therefore, we will take as a calculated temperature of outdoor air for heating a minimum temperature $t_{H}^{\vee}$, which corresponds to the average duration of observations of at least 1 hour. Accordingly, the heating period will be determined by the sum of hours of periods with outdoor air temperatures from the initial value $t_{H .1}=10^{\circ} \mathrm{C}$ up to the settlement.

Amount of thermal energy $W_{C O}$. $\left(\mathrm{KW}^{*}\right.$ hour), necessary to heat a building with the estimated power of the system $Q_{C O .0}$ for the heating period $T$ will be:

$$
W_{C O}=\sum_{i}^{T}\left(Q_{C O t} \cdot \Delta \tau_{t}\right)_{i}=\sum_{i}^{T}\left(Q_{C O .0} \cdot k_{t i} \cdot \Delta \tau_{t}\right)_{i}
$$

where is $k_{t i}=\frac{t_{B}-t_{H i}}{t_{B}-t_{H}^{\vee}}$ - temperature factor determining the required power of the heating

system at the current temperature of the outdoor air $t_{H i}$;

$t_{b}$ - estimated internal air temperature, ${ }^{\circ} \mathrm{C}$;

$\Delta \tau_{t i}$ - period during which the temperature of the outdoor air corresponds to the current value, an hour.

Among the options of heat generators using renewable energy, the most accessible heat pumps "air-water" in which heat is extracted from the outside air and transferred to the heat carrier of the heating system. The main operational feature of such a heat generator is the dependence of the heat performance of the pump and its energy consumption on the temperature of the outdoor air $t_{H i}$ and the required temperature of the coolant $t_{w}$ [6]. Therefore, this factor should be taken into account when assessing the current performance of the heat pump.

The amount of heat energy pumped $W_{H P}\left(\mathrm{KW}^{*}\right.$ hour) depends on its current power $Q_{H P . t}$, duration $T$, temperatures in the heated environment $t_{w}$ and outdoor air $t_{H}$ : 


$$
W_{H P}=\sum_{i}^{T}\left(Q_{H P t} \cdot \Delta \tau_{t}\right)_{i}=\sum_{i}^{T}\left(Q_{H P .0} \cdot k_{t t} \cdot \Delta \tau_{t}\right)_{i},
$$

where is $Q_{H P .0}$ - nominal heat pump power, $\mathrm{KW}$.

$k_{t t}=f\left(t_{w} ; t_{H i}\right)$ - temperature factor taking into account changes in the heat

performance of the pump from the temperature $t_{w}$ and $t_{H}$.

The amount of electrical energy consumed by the diesel pump compressor $W_{K}$. For the period of operation $T$ it will be determined by its current capacity $N_{K . i}$ and the length of operation:

$$
W_{K}=\sum\left(N_{K i} \cdot \Delta \tau_{t}\right)_{i}=\sum_{i}^{T}\left(N_{K 0} \cdot k_{N t} \cdot \Delta \tau_{t}\right)_{i}
$$

where is $N_{K 0}$ - nominal electric power of the heat pump, KW;

$k_{N t}$ - the factor of changes in thermal power from temperature conditions.

Accordingly, useful (effective) thermal energy "produced" by the heat pump over the period $T$ will express how:

$$
\Delta W_{H P}=\left(W_{H P}-W_{K}\right)_{T} .
$$

Factors $k_{t t}$ and $k_{N t}$ although they are derived from the equations of the thermodynamic cycle of the pump, their actual values are more reliable to determine by experienced data. Figure 1 presents the results of production tests of air-water heat pumps with inverter compressors [7].

The temperature factor is a universal indicator of the pump and determines the ability of the pump to pump energy under current conditions. For air-to-water devices, its value, determined by experienced data (Figure 1) matches the formula $(5)[8,9]$ :

$$
k_{t t}=\frac{Q_{H P t}}{Q_{H P .0}}=\exp \left(0,0333 * t_{H i}-0,0062 * t_{w}-0,1289\right)
$$

Temperature of the heating environment $t_{w}$ determined by the type of heating system. For a water system with compact heating devices (radiators or convectors) it is accepted at the level $+55^{\circ} \mathrm{C}$, warm floor heating systems $-+35^{\circ} \mathrm{C}[7]$. 


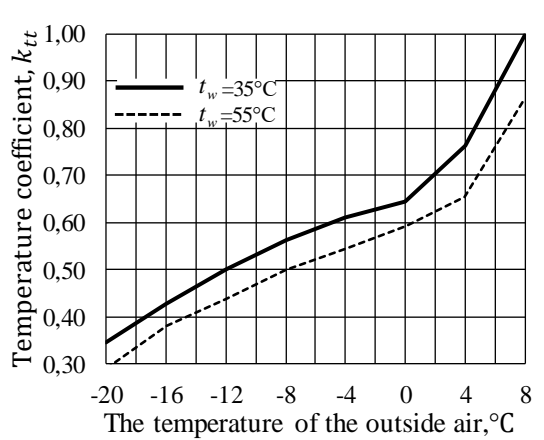

a)

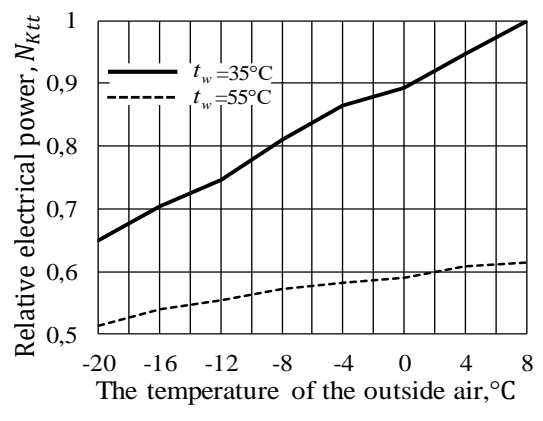

b)

Fig. 1. Temperature ratio dependency $k_{t t}$ a) and power consumption b) $\bar{N}_{K . t t}$ heat pump

from the temperature of the heat-containing environment

The factor of change in the thermal power of the compressor can be presented as dependencies [6]:

$$
\begin{aligned}
& \text { - for } t_{w}=35^{\circ} \mathrm{C}: k_{N t}=\frac{N_{K i}}{N_{K 0}}=0,584+0,0036 * t_{\mu i} \\
& \text { - for } t_{w}=55^{\circ} \mathrm{C}: \quad k_{N t}=\frac{N_{K t}}{N_{K 0}}=0,899+0,0125^{*} t_{\mu i}
\end{aligned}
$$

where is $N_{K t}$ - the current heat capacity of the pump compressor at appropriate temperature values, $\mathrm{KW}$;

$N_{K 0}$ - nominal electric compressor power, $\mathrm{KW}$;

The ratio between the heat capacity of the pump and the electricity consumed is expressed by the energy transformation factor $\mathrm{COP}_{t i}[5]$ :

$$
C O P_{t i}=\frac{Q_{H P i}}{N_{K t i}}=\frac{Q_{H P 0} \cdot k_{t i i}}{N_{K 0} \cdot k_{N t i}}
$$

From empirical dependencies (5) - (7) and ratios (8) we get a generalized expression for the energy transformation factor:

$$
\begin{aligned}
& C O P_{t i}=\exp \left(2,8746+0,00157 \cdot Q_{H P O}-0,064 \cdot t_{W}+0,0417 \cdot t_{H i}+\right. \\
& -0,000071 \cdot Q_{H P 0} \cdot t_{W}-0,000153 \cdot Q_{T H 0} \cdot t_{H i}-0,00022 \cdot t_{W} \cdot t_{H i}+ \\
& \left.+0,00001354 \cdot Q_{T H 0}^{2}+0,00041 \cdot t_{W}^{2}+0,000067 \cdot t_{H i}^{2}\right)
\end{aligned}
$$

Since the characteristics of the heat pump and heating system depend on the temperature of the outside environment and change during the operating period, to determine the amount of energy generated, you need to know the integral values of the works:

$$
P_{Q}=\sum_{i}^{T}\left(k_{t t} \cdot \Delta \tau_{t}\right)_{i} ; \quad P_{N}=\sum_{i}^{T}\left(k_{N t} \cdot \Delta \tau_{t}\right)_{i} \quad \text { и } P_{H}=\sum_{i}^{T}\left(k_{t} \cdot \Delta \tau_{t}\right)_{i} .
$$


The distribution of the duration of the standing temperatures of the outside air is cited in the [10] for the characteristic points of climatic zones. Using this data, on Figure 2-4 integrated distributions $P_{Q}, P_{N}$ and $P_{H}$ for representative geographical areas of "moderate" climate (Moscow), "moderate-cold" climate (Ulan-Ude) and "moderate-warm climate with mild winter" (Novorossiysk).
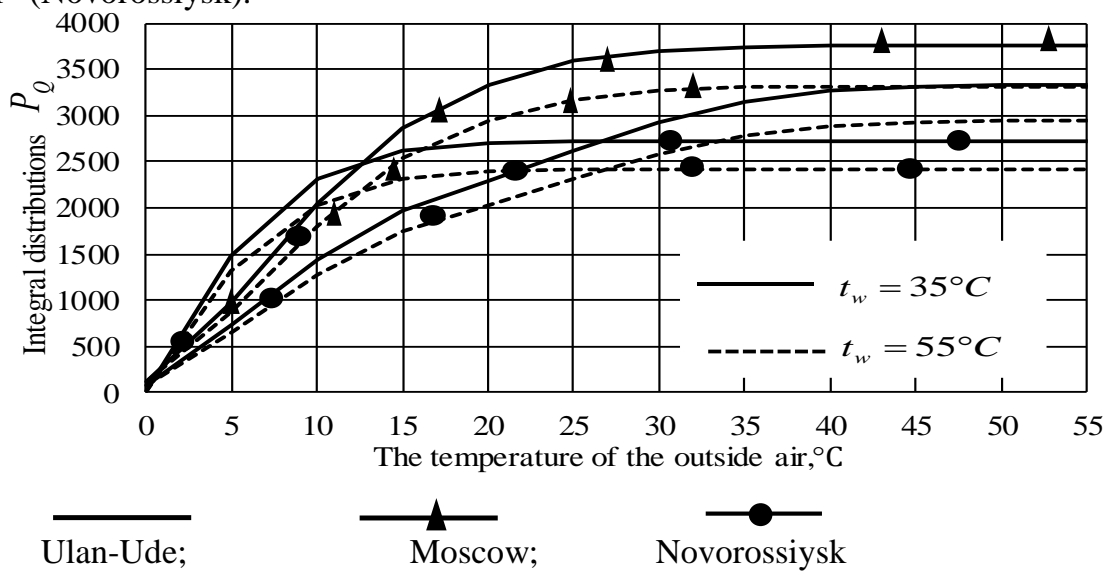

Fig. 2. Integral parameter distributions $P_{Q}$ for items:

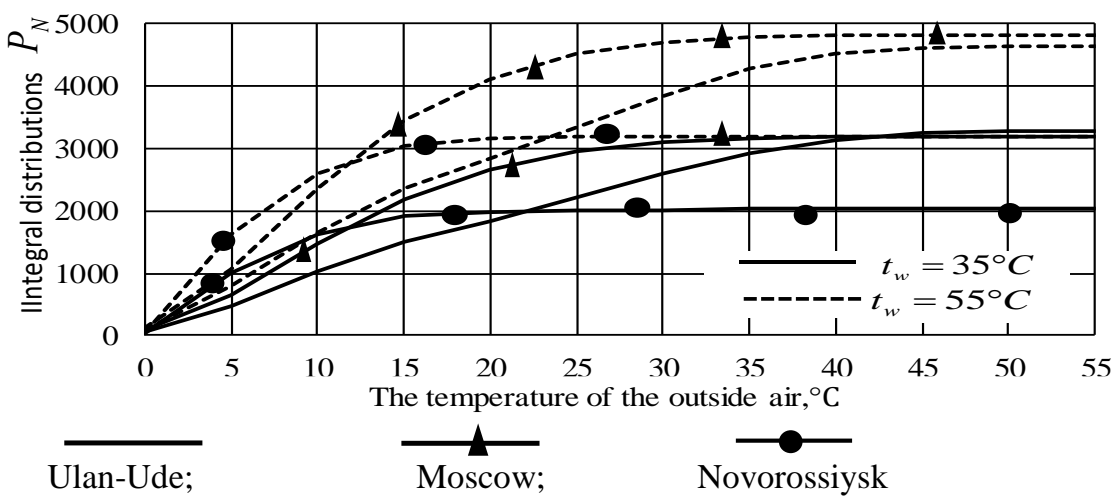

Fig. 3. Integral parameter distributions $P_{N}$ for items:

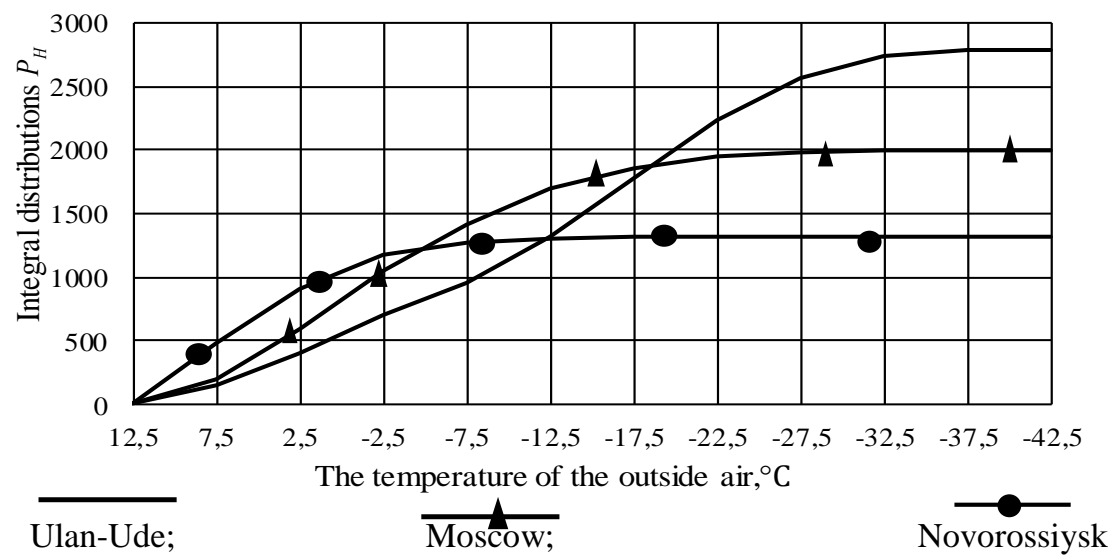

Fig.4. Integral parameter distributions $P_{H}$ for items: 
Integral distributions $P_{Q}$ and $P_{N}$ are characterized by equations such as (11):

$$
P_{N}=b_{o}+b_{1} \cdot t_{H}+b_{2} \cdot t_{H}^{2}+b_{3} \cdot t_{H}^{3}
$$

The odds for the relevant conditions are shown in the Tables 1, 2, 3.

Table 1. Integrated equation ratios $P_{Q}$

\begin{tabular}{|c|c|c|c|c|c|}
\hline \multirow{2}{*}{ Item } & Temperature & \multicolumn{4}{|c|}{ Factors } \\
\cline { 2 - 6 } & $t_{w},{ }^{\circ} \mathbf{C}$ & $\mathbf{b}_{\mathbf{0}}$ & $\mathbf{b}_{\mathbf{1}}$ & $\mathbf{b}_{\mathbf{2}}$ & $\mathbf{b}_{\mathbf{3}}$ \\
\hline \multirow{2}{*}{ Ulan-Ude } & 35 & $-1706,2$ & 154,49 & $-2,5558$ & 0,009681 \\
\cline { 2 - 6 } & 55 & $-1507,2$ & 136,47 & $-2,2578$ & 0,008552 \\
\hline \multirow{2}{*}{ Moscow } & 35 & $-3349,5$ & 261,139 & $-6,2075$ & $-0,04678$ \\
\cline { 2 - 6 } & 55 & $-2948,6$ & 236,88 & $-6,7333$ & 0,04131 \\
\hline \multirow{2}{*}{ Novorossiysk } & 35 & 211,8 & $-443,03$ & $-10,35$ & 0,07602 \\
\cline { 2 - 6 } & 55 & 187,2 & $-383,42$ & $-9,144$ & 0,06736 \\
\hline
\end{tabular}

Tabel 2. Integrated equation ratios $P_{N}$

\begin{tabular}{|c|c|c|c|c|c|}
\hline \multirow{2}{*}{ Item } & Temperature & \multicolumn{4}{|c|}{ Factors } \\
\cline { 3 - 6 } & $\boldsymbol{t}_{w},{ }^{\circ} \mathbf{C}$ & $\mathbf{b}_{\mathbf{0}}$ & $\mathbf{b}_{1}$ & $\mathbf{b}_{2}$ & $\mathbf{b}_{3}$ \\
\hline \multirow{2}{*}{ Ulan-Ude } & 35 & -884 & 94,92 & 0,5078 & $-0,0138$ \\
\cline { 2 - 6 } & 55 & -1680 & 164,88 & $-0,7547$ & $-0,0086$ \\
\hline \multirow{2}{*}{ Moscow } & 35 & -2505 & 201,914 & $-4,7151$ & 0,02482 \\
\cline { 2 - 6 } & 55 & -3980 & 319,4 & $-8,0377$ & 0,04515 \\
\hline \multirow{2}{*}{ Novorossiysk } & 35 & -2355 & 190,57 & $-7,344$ & 0,05341 \\
\cline { 2 - 6 } & 55 & -3814 & 302,87 & $-11,77$ & 0,08595 \\
\hline
\end{tabular}

Tabel 3. Integrated equation ratios $P_{H}$

\begin{tabular}{|c|c|c|c|c|}
\hline \multirow{2}{*}{ Item } & \multicolumn{4}{|c|}{ Factors } \\
\cline { 2 - 5 } & $\mathrm{b}_{0}$ & $\mathrm{~b}_{1}$ & $\mathrm{~b}_{2}$ & $\mathrm{~b}_{3}$ \\
\hline Ulan-Ude & 415,86 & 3,20971 & 1,6925 & 0,04001 \\
\hline Moscow & 796,68 & -87.756 & -0.84581 & 0.004316 \\
\hline Novorossiysk & 703,68 & $-108,16$ & $-5,1269$ & 0,02894 \\
\hline
\end{tabular}

Installation capacity of heat pump compressors $N_{K 0}$ proportional to nominal thermal power and this dependence can be represented by a formula (12) [10]:

$$
N_{K 0}=0,0277+0,257 * Q_{H P .0}-0,00015^{*} Q_{H P .0}^{2} .
$$

So the equations (1-12) make up a system sufficient to analysis energy generation by airwater heat pumps for individual building heating systems.

\section{Discussion of results}

The thermal energy generation analysis will be carried out for the system with the estimated heating capacity and nominal power of the heat pump in the $10 \mathrm{KW}$ for three climatic areas. Changes in the required thermal power of the heating system and the power of the heat generator for variable conditions are shown in Figure 5.

A common characteristic in the capacity ratio is a significant excess of (в 5-8 раз) heat pump performance compared to the required heating capacity in the initial period of the 
heating season at any value of the potential of the coolant. Even taking into account the energy costs of the compressor, this excess is $350-400 \%$. However, as the temperature of the outdoor air decreases, the current power of the heat pump decreases quite sharply and to the estimated temperature is about $16 \%$ from nominal for cold areas to $33 \%$ for «Warm».

a)

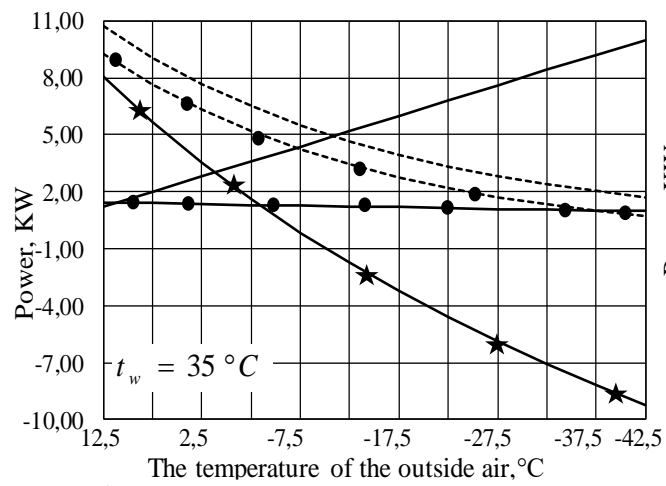

c)

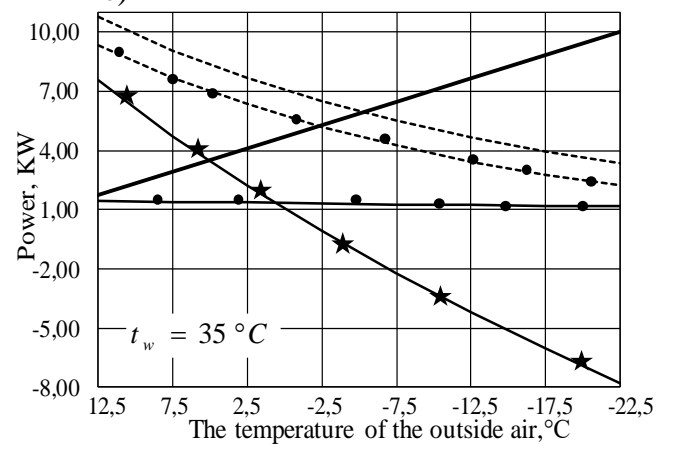

b)

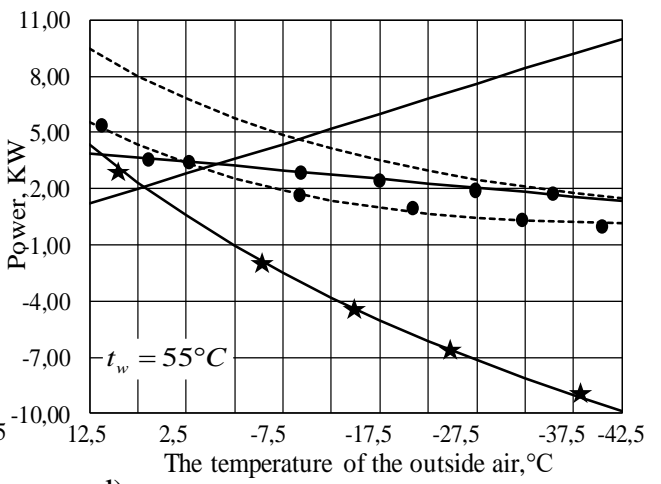

d)

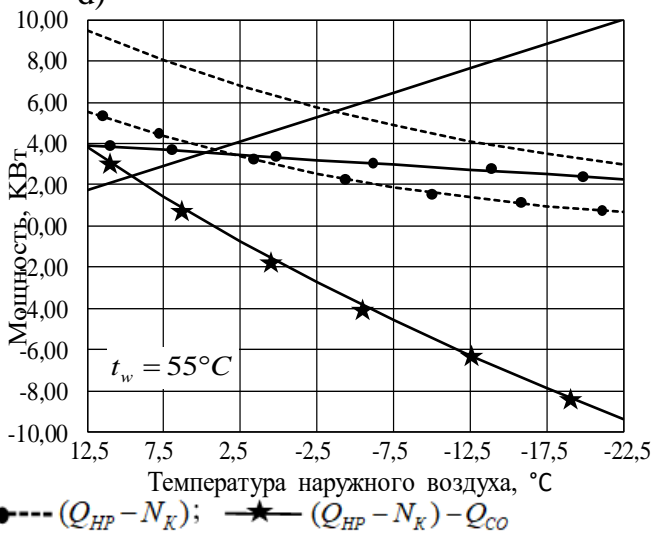

Fig.5. Dependence of current power $(10 \mathrm{KW})$ heating system and heat pump for item conditions: UlanUde и Moscow - a), b) и Novorossiysk - c), d).

And bearing in mind that the required power of the heating system increases, the heat pumpreimburses about $17 \%$ from the required magnitude for the cold climate and about $30 \%$ для «теплого». These figures do not differ significantly (5-8) \% for the various end potentials of the coolant. Interestingly, despite the more favorable working conditions, the power deficit of the heat pump is achieved at a higher temperature of outdoor air for «a warm» area (about $-1^{\circ} \mathrm{C}$ ), than for the colder (about $-8^{\circ} \mathrm{C}$ ). This is because the estimated thermal the power of the heating system is required at a higher temperature air. But in any case, if the nominal power of the heat pump is taken equal to the estimated power of the heating system it is not enough to compensate for the thermal losses of the building. Accordingly, in order for the heating system to function efficiently during the entire period, a heat pump must be installed with a nominal capacity exceeding 8-10 times the estimated heating capacity.

The amount of thermal energy pumped depends not only on the current capacity, but also on the duration of operation in this mode. Figure 6 provides integral heat performance and heating needs during periods that take into account the duration of the working period up to the corresponding outdoor temperature (formulas (1) - (4)). 


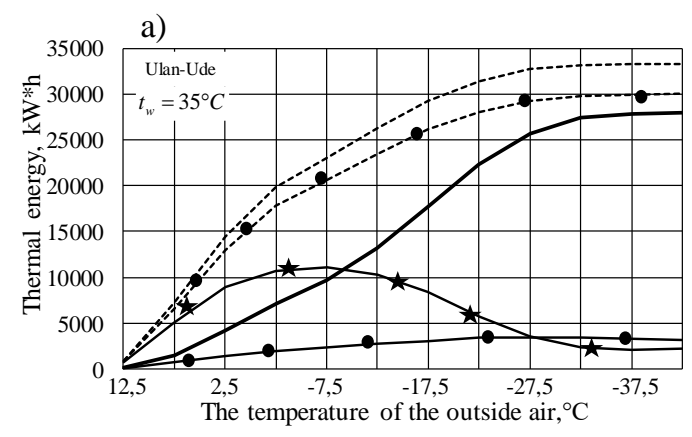

c)

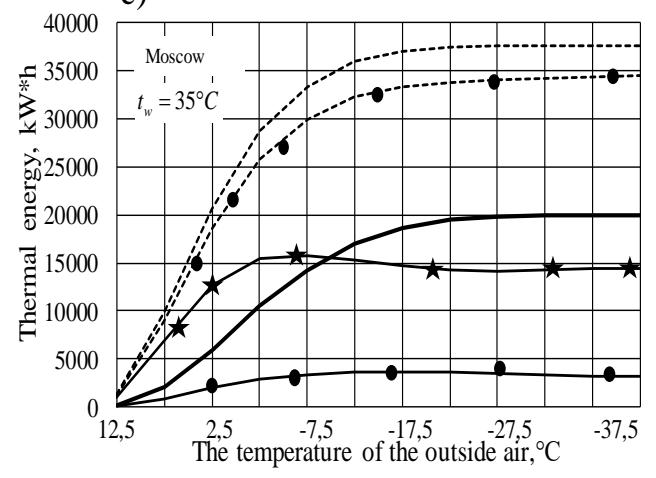

e)

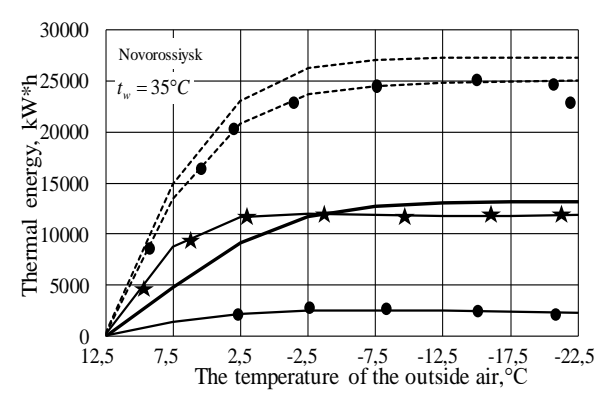

b)

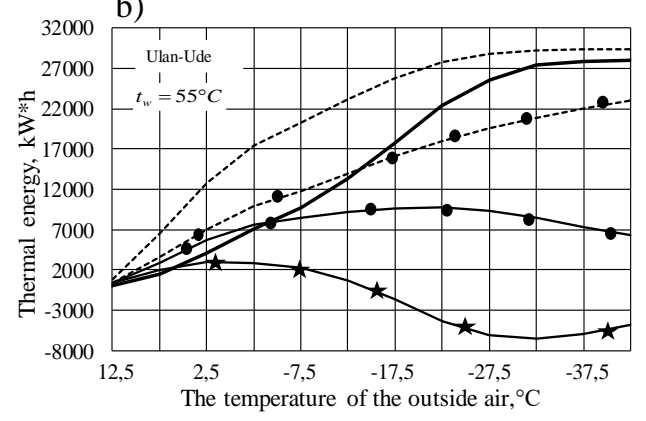

d)

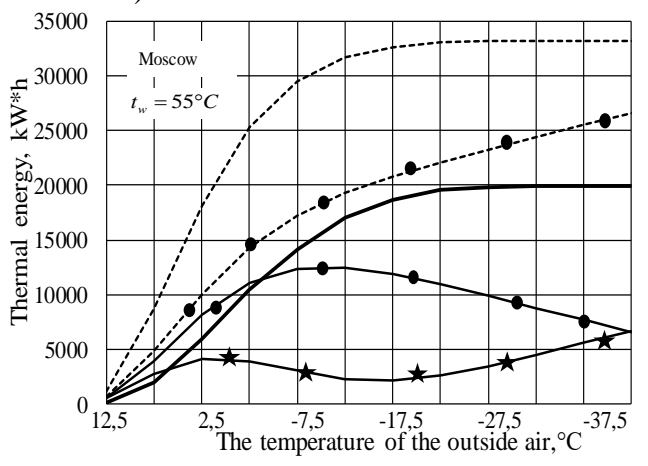

f)

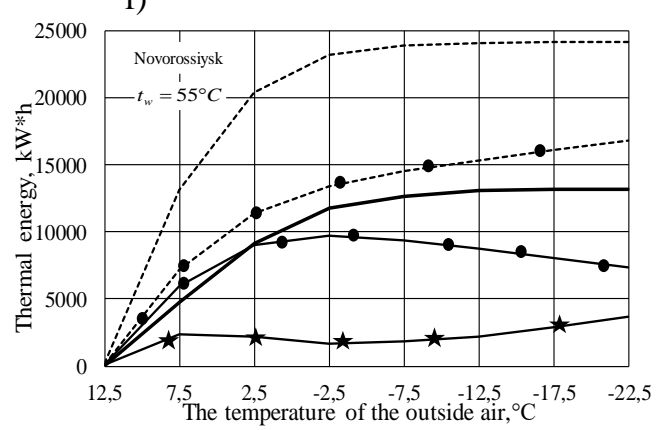

$-W_{C O} ;$----- $W_{H P} ; \multimap W_{K} ; \stackrel{-\bullet---}{\longrightarrow}\left(W_{H P}-W_{K}\right) ; \quad \longleftarrow\left(W_{H P}-W_{K}\right)-W_{C O}$

Fig.6. Integral values of thermal energy of the heating system and heat pump

The results of the calculations show that the total amount of thermal energy pump pumped during the operational period far exceeds the total heating requirement for all climatic areas.

So for a "warm" climate, the excess of heat pump performance is $108 \%$ при $t_{w}=35^{\circ} \mathrm{C}$ and $76 \%$ at $t_{w}=55^{\circ} \mathrm{C}$. Accordingly for "moderate" and "moderate-cold" $88 \%$ и $66 \%$ and $19 \%$ and $5 \%$.

Given the cost of electricity to the pump, these rates are slightly reduced to $90 \%$ at $t_{w}=35^{\circ} \mathrm{C}$ и $28 \%$ at $t_{w}=55^{\circ} \mathrm{C}$ («шаrm climate») и $73 \%$ and $33 \%$ («temperate »). And only for the "moderate-cold" climate the total efficient heat performance of the pump becomes commensurate with the need for heating at $t_{w}=35^{\circ} \mathrm{C}$ and there is even a lack of energy in the production of high-potential heat $\left(t_{w}=55^{\circ} \mathrm{C}\right)(-17 \%$.). 
a)

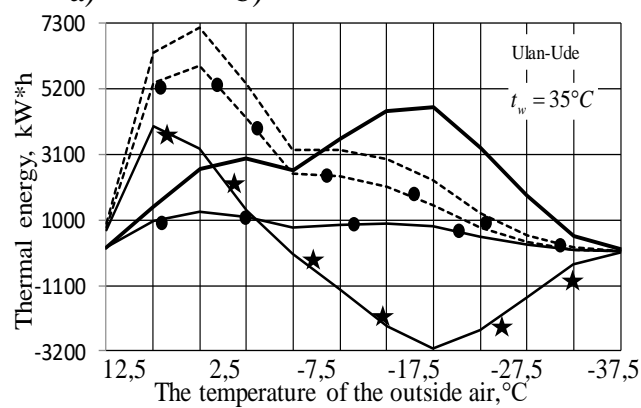

c)

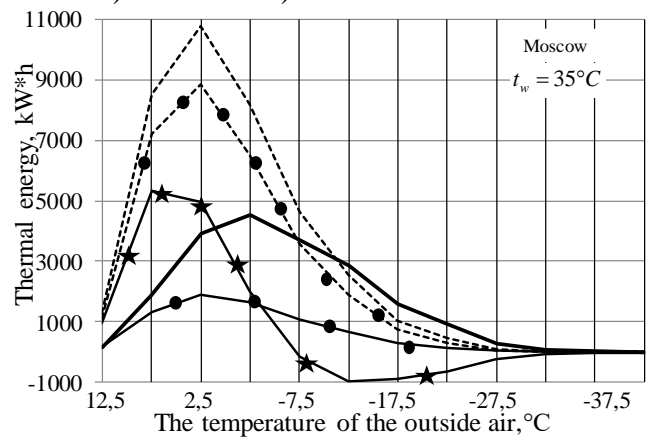

f)

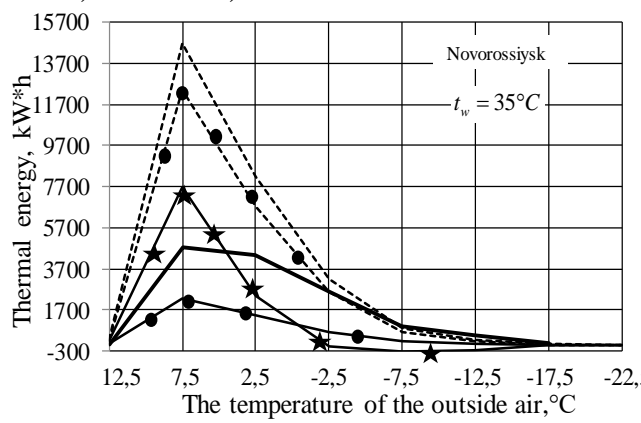

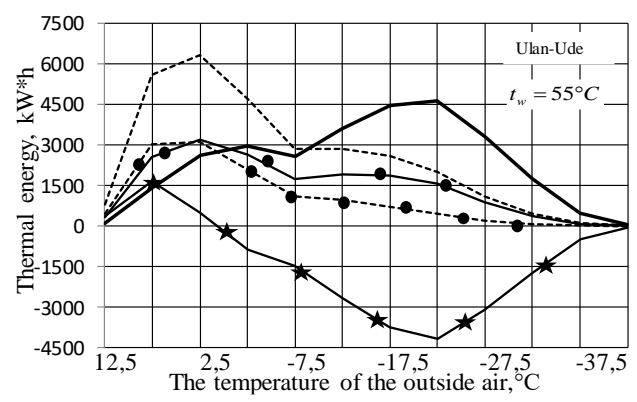
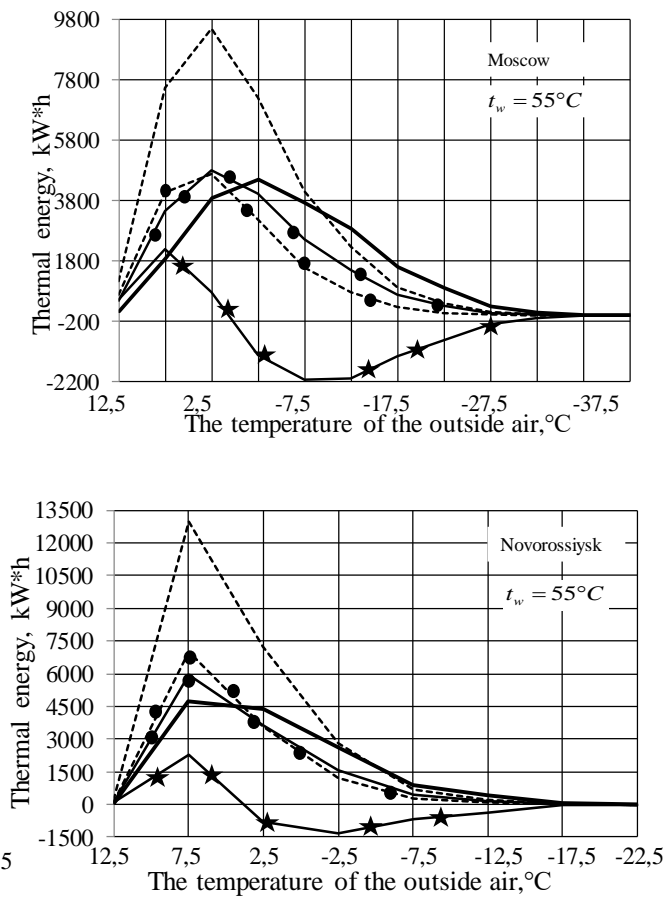

$\left(W_{H P}-W_{K}\right) ; \quad \star\left(W_{H P}-W_{K}\right)-W_{C O}$

$-W_{C O}$

$W_{H P} ; \multimap W_{K}$;

Fig.7. Discrete values of heat energy of the heating system and heat pump

Interestingly, the proportion of the total amount of energy spent on the pump during the heating period is greater for «warm» areas (18-56) \% (Novorossiysk), than for the "cold" (1223) \% (Ulan-Ude).

Production and consumption of thermal energy at intervals with a certain average temperature of outdoor air (step into $5^{\circ} \mathrm{C}$ ) given on Figure 7. The discrete values of the energies also show the excess amount of energy produced by heat pumps at low temperatures of outdoor air - from (360-430) \% before (45-10) \% depending on the outside temperature and the level of energy supplied. With the drop in air temperature the ratio between the energy produced and consumed changes dramatically in favor of the latter and already starting from temperatures close to negative, the pump's performance is not enough to compensate for the building's heat loss. The boundaries of this ratio depend not only on the characteristics of the pump, but also on the distribution of the duration of the standing periods 
of the outer temperature and the calculation. In a cold climate, a negative balance comes $t_{H}=-11^{\circ} \mathrm{C}$ for $t_{w}=35^{\circ} \mathrm{C}$ and $t_{H}=-8^{\circ} \mathrm{C}$ at $t_{w}=55^{\circ} \mathrm{C}$, and in the "warm" $t_{H}=-6^{\circ} \mathrm{C}$ for $t_{w}=35^{\circ} \mathrm{C}$ and $t_{H}=-4^{\circ} \mathrm{C}$ at $t_{w}=55^{\circ} \mathrm{C}$. It would seem that paradoxical indicators are explained by different estimated heating temperatures $\left(t_{H O}=-42,5^{\circ} \mathrm{C}\right.$ and $\left.t_{H O}=-22,5^{\circ} \mathrm{C}\right)$ and, accordingly, an earlier onset of the required heating capacity close to the estimated.

Если рассматривать эти соотношения для «полезной» тепловой производительности $\left(W_{H P}-W_{K}\right)$, то границы эффективного применения насоса существенно смещаются к более высоким температурам: $t_{H}=-5^{\circ} \mathrm{C}$ для $t_{w}=35^{\circ} \mathrm{C}$ и $t_{H}=-1^{\circ} \mathrm{C}$ при $t_{w}=55^{\circ} \mathrm{C}$ - «холодный» климат, и $t_{H}=-1^{\circ} \mathrm{C}$ для $t_{w}=35^{\circ} \mathrm{C}$ и $t_{H}=+4^{\circ} \mathrm{C}$ при $t_{w}=55^{\circ} \mathrm{C}$ - «теплый» климат.

Provided high-potential energy is produced $t_{w}=55^{\circ} \mathrm{C}$, The relatively low energy of the heating system at temperatures close to the initial temperature can only be achieved by the energy consumed by the heat pump compressor (Figure 7b), d), e)).

The figures are given for the estimated capacity of the heating system equal to $10 \mathrm{~kW}$. But, the presence of proportionality between the energy characteristics of technical elements and systems, suggests that at other heating capacity there are similar ratios.

\section{Conclusion}

The analysis of thermal energy production by heat pumps shows on the one hand serious shortcomings of power and discrete performance of thermal energy at low temperatures of the heat-containing environment, but at the same time a significant excess of the total energy received during the period of operation, even in relatively cold climatic conditions. These features of heat production and consumption by the systems under consideration allow us to draw the following conclusions:

- the use of heat pumps in heating systems as the only source of heat is possible only with the ratios of nominal pump capacity and estimated heating capacity of at least 8-10. This can have a significant impact on the economic characteristics of the system;

- Excess thermal energy produced by the pump in one system cannot be usefully used. But the excess electrical energy consumed at the same time must be paid for at existing tariffs, which will reduce the cost-effectiveness of the method;

- a significant positive balance in pump heat generation over a sufficiently long period opens up the possibility of using this source for heating other systems - hot water or parallel other heating systems. And this may prove to be a promising direction for improving the profitability of the system as a whole;

- exceeding the heat performance of the pump over the required heating opens up the possibility of using heat in the battery system and shortening the active life of the heat generator.

Of course, the proposed method has an "estimated" level, but allows to predict the possible effects of the use of heat pumps and choose promising schemes of technical systems for the use of renewable energy sources.

\section{References}

1. S.K. Luneva, A.S. Chistovich, I.H. Emirov, Tech and Technology Service Problems Magazine, 2, 15 
2. Y.V. Petin, New generation of heat pumps for heating purposes and efficiency of their use in Russia (Novosibirsk: Energy, 2004)

3. Kochev, M. Sokolov, E. Kocheva, A. Moskaeva, Energy-saving measures in buildings considered as monuments of history and architecture (Compilation: MATEC Web of conferences Ser. «International conferences on Research in Mechanical Engineering Sciences, RiMES2017», 2018)

4. Vasilyev, Heat supply to buildings and structures using low potential thermal energy of surface layers of land (Border Publishing House. Moscow, 2006)

5. D. Ray D, D. McMichael, Heat pumps (M: Energyizdat, 1982)

6. S.I. Kuzmin, N.A. Ivshina, IOP CS: MSaE , 1, 012047 (2020)

7. Graphic performance of DHP-A-type heat pumps (Test materials at the manufacturer, 2020)

8. S.I. Kuzmin, N.A. Ivshina, IOP CS: MSaE, 1, 012034 (2020)

9. S.I. Kuzmin, A.V. Zateeva, IOP CS: MSaE, 1, 012033 (2020)

10. GOST 16350-80 Climate of the USSR, https://docs.cntd.ru/document/1200004579 